\title{
Water quality of road runoff in the Blue Mountains, NSW, Australia
}

\author{
S. Riley ${ }^{1}$, S. Shrestha ${ }^{1}$, P. Hackney ${ }^{2}$ \& R. A. Mann ${ }^{3}$ \\ ${ }^{1}$ Sustainable Engineering and Technology Research Group, \\ University of Western Sydney, Australia \\ ${ }^{2}$ NSW Water Solutions, NSW Department of Commerce, Australia \\ ${ }^{3}$ Science Section, Sydney Catchment Authority, Australia
}

\begin{abstract}
The Blue Mountains of New South Wales, Australia is a populated area that includes a world heritage listed area. There is concern about the impact on the national parks of the pollution that may result from stormwater runoff from the roads in the area. A rainfall simulation experiment was undertaken on two areas with paved and unpaved road segments. Water quality parameters were examined, including metals, organic pollutants and sediment load. The hydrology and the hydraulics of the road surfaces were also studied. The paper reports on the experimental set-up at both sites and also the main results. Some recommendations are made concerning the management of the roads.
\end{abstract}

Keywords: road erosion, rainfall simulation, water quality.

\section{Introduction}

Unpaved roads contribute to sediment and pollutants discharged into bushland and National Parks in the Blue Mountains. The erosion associated with unpaved roads is well studied and there are several models that have been applied to predict erosion (Gruszowski et al. [1], Luce and Wemple [2], Zaiegler et al. [3]). Less is known of the runoff water quality in paved areas. In recognition of the issues associated with runoff from roads the NSW State government funded a program to pave roads in the area. The cost and environmental efficacy of the road sealing and erosion control program needed to be quickly established and data required to develop runoff-water quality-environmental impact models to 
translate the work undertaken in specific locations in the Blue Mountains to other areas.

Several methods of ameliorating the off-site impacts of runoff from roads have been discussed, but the cost-effectiveness is not well known. There can be no doubt that road surfacing and verge protection will improve water quality, but the extent of this improvement is open to question and needs to be clearly validated. There is also a lack of calibrated models that can be used to undertake theoretical studies of the improvement in the water quality as a result of the works. To overcome these difficulties of achieving meaningful data in a short period a rainfall simulation was used.

Key advantages of the use of rainfall simulators are (Riley and Hancock [4]):

1. the replication of simulated storm conditions, which removes problems associated with the spatial and temporal variability that occurs in natural storms;

2. control over the time of the experiment, not having to wait for storm events nor provide stand-by resources to monitor an event when it occurs

3. the cost-efficiency of rainfall simulator studies, which has been clearly demonstrated in many studies

4. the opportunity to adjust experiments and repeat them when real-time analysis of results suggests improvements, opportunities or the need for further measurements

Details of the experiments and the results are presented. Two sites were examined, one in the lower Blue Mountains and the other in the upper Blue Mountains.

\section{Method}

The experiment consisted of rainfall simulation:

- at two sites - Upper (Medlow Bath) and Lower (Springwood) Blue Mountains

- at two stages of road paving (paved and unpaved)

- for different rainfall intensities ( ranging from <1year to 5 year annual recurrence intervals)

- with a rainfall duration that equals the time of concentration plus 5 to 10 minutes to study long-term flushing effects

Parameters measured during the tests included:

- rainfall depth, duration and intensity

- runoff rates

- runoff water quality ( $\mathrm{pH}$, Conductivity, TSS, $\mathrm{Cu}, \mathrm{Pb}, \mathrm{Zn}, \mathrm{PAH}$ )

- erosivity

In addition, observations were undertaken on:

- sources of erosion

- efficacy of erosion control strategies

- diffusion of pollutants along water courses 
Sufficient length of road was examined (approximately 50m) that issues related to spatial variability and its effects on results were minimised.

Soil/geotechnical surveys were undertaken to define the nature of the materials and its pollution producing potential. The following were undertaken at each site:

- textural analysis (particle size analysis)

- $\mathrm{TOC}, \mathrm{Cu}, \mathrm{Pb}, \mathrm{Zn}, \mathrm{pH}$, Salinity analysis of sediment and road surface material

- density

- erosion resistant coverage (geofabric, vegetation etc)

The plans of the field sites are shown in Figures 1 and 2. Both sites were surveyed in detailed, at $5 \mathrm{~cm}$ elevation accuracy, in order to determine accurately determine micro-patterns in topography.

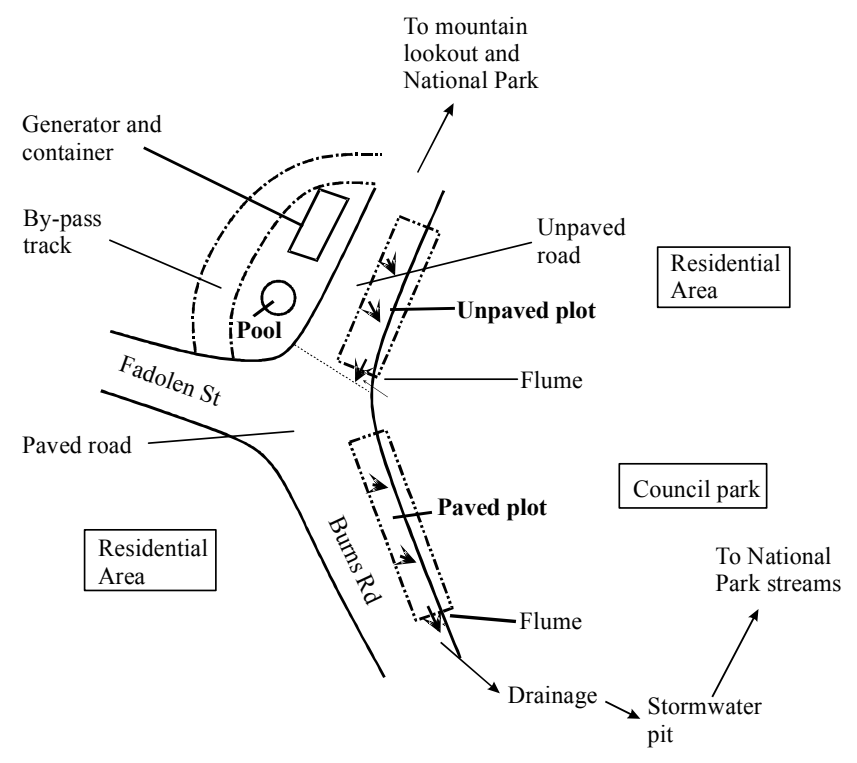

Figure 1: $\quad$ Field site at Springwood, Lower Blue Mountains.

\subsection{Simulation program}

Rainfall simulations ran for 10 minutes and at least 30 minutes was allowed between simulations. At both sites only half the road could be used as vehicle access had to be provided along the roads at all time. Samples of runoff, water quality and hydraulic measurements were taken ever 30 seconds except when it was obvious that no changes were occurring. Sites were sampled on the road pavement as well as at the outlet of the whole section of road (the gutter sites) in order to disentangle the contributions of the two parts of the road. Running separate experiments to distinguish the hydraulic and geochemical characteristics of the pavement and the gutters would have increased the field time and was not the most efficient use of resources. 


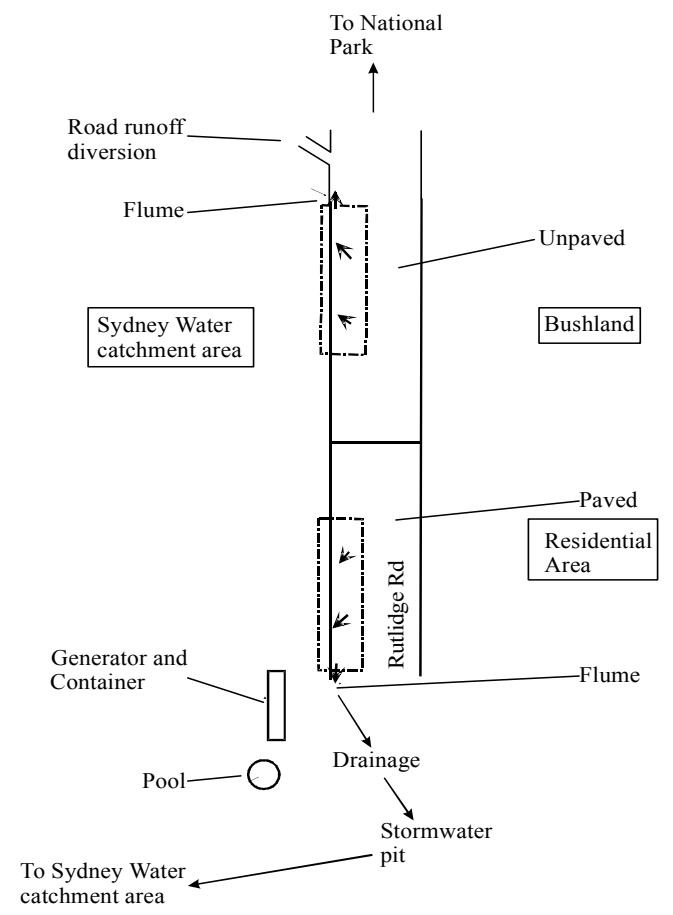

Figure 2: $\quad$ Field site at Medlow Baths, Upper Blue Mountains.

The rainfall simulation sequence was identified from the above. The rainfall intensities of targeted recurrence intervals of the simulated rainfalls was estimated from Intensity-Frequency-Duration data for Springwood and Medlow Bath and represented mean rainfall intensities of between 7 and $108 \mathrm{~mm}$ per hour.

Detailed particle size analyses were undertaken of samples swept from the surface of the road as well as that in the sampled runoff using a Malvern Instruments MasterSizer 2000. Details of the analytical techniques are given in Riley et al. [5].

\section{Results}

The sediment discharges for all the sites show an increase ae discharge increases, and then a decline as the runoff progresses at near constant discharge. The sediment concentrations tend to be high during the first few minutes of runoff and decline significantly as the runoff continues. Thus, while the concentration of the first flows are high (the "first flush") the peak of the sediment discharge tends to occur some time after the peak concentration, but not always at the time the peak water discharge occurs.

There is considerable variation in sediment concentration and sediment discharge during a runoff event (see Riley et al [5] for details). There are many 
reasons for this, but they are essentially related to the spatial and temporal variations in the entrainment of sediment. Pulses of sediment were seen moving along the flow lines and at times some areas appear to be contributing more sediment than at other times.

The sediment discharges and sediment concentrations are much higher in the gutters than on the pavements, sometimes by more than 100 times. The sediment discharges from the unpaved sections are also orders of magnitude higher than those from the paved sections.

The particle size analysis could not be undertaken on sediment loads of paved road, due to insufficient sediment in the runoff from these roads (see previous section). In order for particle sizing to be carried out on these samples a large water sample would have to be collected and then filtered.

The data show:

a) There is very little difference in particle size distribution within each experimental run for all sites

b) There is very little difference in particle size distribution between experimental runs at each experimental location (Springwood and Medlow Bath)

c) There is little difference in particle size distribution between Springwood and Medlow Bath

The particle size distribution of the samples depends on:

i) The particle size distribution in the material of the road

ii) The erosivity of the rainfall and the power of the water transporting the road material

Since the Springwood and Medlow Bath sites had different types of material making up the road but still produced very similar particle size distributions, it seems likely that the controlling factor during runoff from the road is the hydraulics of the erosion process. The velocity of the water will be dependent on the slope of the road. While the road surfaces are dominated by coarse grained material ( $>64$ micron) the fine grained material ( $<64$ micron) is preferentially eroded from the site.

Table 1: Average ratio between unpaved and paved roads concentrations of metals at Springwood, samples collected from the gutter.

\begin{tabular}{|c|c|c|c|c|c|c|}
\hline $\begin{array}{c}\text { Run } \\
\text { Number }\end{array}$ & $\begin{array}{c}\mathrm{Cu} \\
\text { (Total) }\end{array}$ & $\begin{array}{c}\mathrm{Cu} \\
\text { (Filtered) }\end{array}$ & $\begin{array}{c}\text { Pb } \\
\text { (Total) }\end{array}$ & $\begin{array}{c}\text { Pb } \\
\text { (Filtered) }\end{array}$ & $\begin{array}{l}\mathrm{Zn} \\
\text { (Total) }\end{array}$ & $\begin{array}{c}\mathrm{Zn} \\
\text { (Filtered) }\end{array}$ \\
\hline 1 & 1.81 & 1.30 & 0.35 & 0.62 & \multirow{4}{*}{$\begin{array}{l}1.67 \\
1.73 \\
3.10 \\
1.41\end{array}$} & 2.78 \\
\hline 2 & 4.91 & 0.80 & 1.63 & 1.10 & & 0.69 \\
\hline 3 & 6.13 & 5.73 & 3.76 & 4.05 & & 3.83 \\
\hline 4 & 2.73 & 2.60 & 2.43 & 1.25 & & 1.19 \\
\hline Average & 3.89 & 2.61 & 2.04 & 1.75 & 1.98 & 2.12 \\
\hline
\end{tabular}

Runs 1 and 2 - rainfall intensities with ARI less than $1 \mathrm{yr}$

Run 3 - rainfall intensity with ARI of 18 months

Run 4 - rainfall intensity with ARI of 4 yrs 
The concentrations of heavy metals in the total sample were in some cases very much higher than the filtered samples. As the majority of particles are less than 64 microns in diameter the data seem to be suggesting in these cases that the majority of heavy metal contaminants are associated with the coarse fraction. This is the converse of what is normally found and will have to be checked with some care. The levels of metals in water discharged from the unpaved plots are generally much higher than those seen in water discharged from the paved sites

Table 2: Average ratio between unpaved and paved roads concentrations of metals at Medlow Bath, samples collected from the pavement.

\begin{tabular}{|c|c|c|c|c|c|c|}
\hline $\begin{array}{c}\text { Run } \\
\text { Number }\end{array}$ & $\begin{array}{c}\text { Cu } \\
\text { (Total) }\end{array}$ & $\begin{array}{c}\text { Cu } \\
\text { (Filtered) }\end{array}$ & $\begin{array}{c}\text { Pb } \\
\text { (Total) }\end{array}$ & $\begin{array}{c}\text { Pb } \\
\text { (Filtered) }\end{array}$ & $\begin{array}{c}\text { Zn } \\
\text { (Total) }\end{array}$ & $\begin{array}{c}\text { Zn } \\
\text { (Filtered) }\end{array}$ \\
\hline 1 & $\begin{array}{c}\text { not } \\
\text { available }\end{array}$ & 7.54 & $\begin{array}{c}\text { not } \\
\text { available }\end{array}$ & 2.69 & $\begin{array}{c}\text { not } \\
\text { available }\end{array}$ & 2.50 \\
\hline 2 & 2.80 & 1.83 & 0.86 & 0.63 & 0.88 & 0.40 \\
\hline 3 & 2.92 & 2.90 & 1.11 & 1.35 & 1.22 & 1.73 \\
\hline 4 & $\begin{array}{c}\text { not } \\
\text { available }\end{array}$ & $\begin{array}{c}\text { not } \\
\text { available }\end{array}$ & $\begin{array}{c}\text { not } \\
\text { available }\end{array}$ & $\begin{array}{c}\text { not } \\
\text { available }\end{array}$ & $\begin{array}{c}\text { not } \\
\text { available }\end{array}$ & $\begin{array}{c}\text { not } \\
\text { available }\end{array}$ \\
\hline & & & & & & 1.05 \\
\hline Average & 2.86 & 4.09 & 0.99 & 1.56 & & 1.54 \\
\hline
\end{tabular}

Runs 1 and 2 - rainfall intensities with ARIs less than 1 year

Run 3 - rainfall intensity with ARI of 2 years

Run 4 - rainfall intensity with ARI of 5 years

\section{Discussion}

The concentrations of the metals lead, copper and zinc in the upper $60 \mathrm{~mm}$ of the road material are sufficient to account for the concentrations found in the runoff samples. Some metals appear, in some instances, to be preferentially attached to large particles, which is unusual.

The concentrations of metals in the sediment, if in soluble form, would exceed guidelines. However, the metals are largely absorbed onto the sediment and unless they are deposited in a geochemical environment that favours their release (say a low $\mathrm{pH}$ condition) then they are unlikely to represent a problem to receiving systems in the short term. However, benthic feeding organisms that digest sediment may well uptake these metals thus introducing them into the food chain. In addition, there is likely always to be some exchange of metals from the sediment surfaces into the water, and over a period of time a significant proportion of the metal in the sediment may be released.

Toxicity tests should be undertaken on the materials from the road surface to establish the concentrations of the sediments, with their associated metals, that have an environmental impact through the associated metals. Clearly there are environmental impacts arising from the high sediment loads and turbidity, which are separate issues from metal toxicity. 
One outcome of the results of this study is the ability to assess the sediment load discharged from the roads into the adjacent Blue Mountains bushland. In the following it is assumed (from Council supplied data) that there are $91 \mathrm{~km}$ of unpaved road and $77 \mathrm{~km}$ of paved road.

The following table (Table 3) presents an estimate of the load from all roads in the Blue Mountains City Council (BMCC) area using the data from the pavement and gutters measurements at Springwood and Medlow Bath. The range in values presented in the tables arise from the differences among the sites and changes in sediment loads among simulation runs at each site.

Table 3: Estimates of total sediment load from BMCC roads per $\mathrm{mm}$ of rainfall excess for individual runs at each site.

\begin{tabular}{|c|c|c|c|c|c|}
\hline $\begin{array}{l}\text { Unpaved } \\
\text { or Paved }\end{array}$ & $\begin{array}{c}\text { Run } \\
\text { Number* }\end{array}$ & \begin{tabular}{lr}
\multicolumn{2}{c}{ Springwoo } \\
d & gutter, \\
kg &
\end{tabular} & $\begin{array}{l}\text { Springwoo } \\
\text { d } \\
\text { pavement, } \\
\text { kg }\end{array}$ & $\begin{array}{l}\text { Medlow } \\
\text { Bath } \\
\text { Gutter kg }\end{array}$ & $\begin{array}{l}\text { Medlow } \\
\text { Bath } \\
\text { pavement, } \\
\text { kg }\end{array}$ \\
\hline Unpaved & 1 & 522.7 & $\begin{array}{c}\text { Not } \\
\text { available }\end{array}$ & 1106.3 & 1508.6 \\
\hline Paved & 1 & 330.1 & $\begin{array}{c}\text { Not } \\
\text { available }\end{array}$ & 3.7 & $\begin{array}{c}\text { Not } \\
\text { Available }\end{array}$ \\
\hline Ratio & & 1.6 & & 298.2 & \\
\hline Unpaved & 2 & 459.4 & 1621.8 & 1038.0 & 13473.3 \\
\hline Paved & 2 & 215.6 & 63.3 & 2.0 & 33.5 \\
\hline Ratio & & 2.1 & 25.6 & 527.00 & 401.7 \\
\hline Unpaved & 3 & 451.2 & 217.4 & 735.5 & 1346.8 \\
\hline Paved & 3 & 341.4 & 10.4 & 9.1 & 20.9 \\
\hline Ratio & & 1.3 & 20.8 & 80.6 & 64.6 \\
\hline Unpaved & 4 & 264.2 & 162.2 & 772.7 & 791.2 \\
\hline Paved & 4 & 65.7 & 3.6 & 8.9 & 14.8 \\
\hline & & 4.0 & 45.5 & 86.4 & 53.4 \\
\hline
\end{tabular}

*Refer to tables 1 and 2 for corresponding run numbers.

The data show that there are substantial differences in the estimates of total sediment load for each mm of runoff. As expected, they clearly demonstrate that the sediment loads from paved roads are much less than those from unpaved roads, for all sites and all rainfall conditions.

The general trend in the data suggest that there is between 0.5 and 2 tonne of sediment discharged into the bushland for each $\mathrm{mm}$ of rainfall excess. In some cases the losses may be much higher. The unpaved pavement data for Medlow Bath suggest that the sediment discharge may be as high as 13 tonnes for each $\mathrm{mm}$ of rainfall excess. The data support the estimate that some 5000 tonne of 
sediment are discharged into the National Park each year from unpaved roads. The available information from this study indicates that the actual sediment load is between 500 and 10,000 tonnes.

Care must be taken in extrapolating the simulator data. There is no account for cross-road drainage and associated erosion in the experimental design. Crossroad drainage can excavate large rills which may account for substantial sediment loads. No account is taken of differences in the slope of the road or the nature of the road base nor of the impact on erosion of road traffic during runoff events. These factors are the subject of stage two of the project. Hence, the data presented herein for the sediment loads discharged into the National Park must be taken as MINIMUM values, rather than estimates of the total sediment load.

An analysis of the load of metals discharged from all sites is difficult. Few analyses are available for each runoff event, so estimates of loads will be approximations at the best. The estimates of load, per unit area, per unit rainfall excess, have been extended to calculate the load of metals exported from all paved and unpaved roads in the Blue Mountains Municipality. The calculations are undertaken for the three sets of data. There were insufficient samples collected from the pavements at Medlow Bath to undertake this analysis (for example of estimates see Table 4).

Table 4: $\quad$ Estimated load of metals per mm of runoff for $91 \mathrm{~km}$ of unpaved road and $77 \mathrm{~km}$ of paved road using Springwood, gutter data.

\begin{tabular}{|c|c|c|c|c|}
\hline $\begin{array}{l}\text { Unpaved or } \\
\text { Paved }\end{array}$ & $\begin{array}{c}\text { Run } \\
\text { Number* }\end{array}$ & $\mathbf{Z n , ~ g}$ & $\begin{array}{l}\mathbf{C u} \\
\mathbf{g}\end{array}$ & $\begin{array}{l}\mathbf{P b} \\
\mathbf{g}\end{array}$ \\
Unpaved & 1 & 75.2 & 5.8 & 11.6 \\
Paved & 1 & 44.3 & 31.3 & 32.3 \\
Ratio & & 1.7 & 0.2 & 0.4 \\
& & & & \\
Unpaved & 2 & 47.8 & 8.7 & 27.1 \\
Paved & 2 & 27.9 & 17.7 & 16.8 \\
Ratio & & 1.7 & 0.5 & 1.6 \\
& & & & \\
Unpaved & 3 & 34.2 & 6.1 & 25.8 \\
Paved & 3 & 12.4 & 26.2 & 10.5 \\
Ratio & & 2.8 & 0.2 & 2.5 \\
& & & & \\
Unpaved & 4 & 17.6 & 3.7 & 14.9 \\
Paved & 4 & 13.3 & 14.5 & 6.5 \\
Ratio & & 1.3 & 0.3 & 2.3 \\
\hline
\end{tabular}

*Refer to Tables 1 and 2 for rainfall intensities corresponding to run numbers. 
The total metal loads are of the order of ten to 100 grams per mm of runoff. These may not appear to be high, but when multiplied by the rainfall excess of the Blue Mountains, of the order of $500 \mathrm{~mm}$ or more, they suggest that ten to $100 \mathrm{~kg}$ of metals are washed into the receiving systems along the roads, via detention basins, streams or wetlands. The results suggest that while there is no particular pattern evident, the ratios of the loads from paved and unpaved sites suggests that the metal loads, in general, are significantly reduced by the road paving, probably a result of the decrease in sediment discharge.

The data suggests that the porous rolled-bitumen gutter at Medlow Bath had several advantages. It increased storage in the road catchment, it attenuated the hydrograph and it probably contributed to a reduction in some pollution, although the last is less certain. Rolled-bitument gutters are common in minor roads of the Blue Mountains.

The high concentrations of pollutants in runoff occurred in the first 5 to 10 minutes of the storms. Successive storms, close together in time had, much smaller pollutant loads than the first storm in the sequence. This is because there was insufficient time for natural weathering processes and road traffic to accumulate material on the road surface that could be removed by the next storm. These data suggest that there is considerable value in small first-flush retention basins along roads. These basins would hold the more concentrated pollutant runoff. If there was a long-enough period for more pollutants to build-up on the road it is highly likely that this would also be sufficient time for infiltration and evaporation to empty the basins. Thus there would be an empty basin with capacity to receive first-flush runoff from the next significant storm.

There is merit in hardening the gutters if funds are insufficient to pave the whole road. The gully-erosion in the gutters is evident from the increase in sediment discharge per unit area between the gutters and the pavement (in most cases). This implies that more sediment per unit area is derived from the gutters than from the pavement. Observations support this assessment, as it is obvious that the deepest erosion takes place in the gutters, where the water concentrates. Nevertheless, there is significant erosion on the pavement.

\section{Conclusion}

It was demonstrated with field data from rainfall simulation experiments that there are substantial discharges of sediment and pollutants into the Blue Mountains National Park from erosion of unpaved roads and that paving roads reduces the pollutant and sediment loads discharged into National Parks by ten to 100 times (and more). There are some opportunities to improve road design, although these need to be tested.

\section{References}

[1] Gruszowsk, K. E., Foster I. D. L., Lees J. A. and Charlesworth, S. M 2003 Sediment sources and transport pathways in a rural catchment, Herefordshire, UK Hydrological Processes, 17 (13), 2665-2681 
[2] Luce, C.H. and. Wemple, B.C 2001. Introduction to special issue on hydrologic and geomorphic effects of forest roads Earth Surface Processes and Landforms 26 (2) 111-113

[3] Ziegler, A.D., Giambelluca, T.W., and Sutherland, R.A. 2002 Improved method for modelling sediment transport on unpaved roads using KINEROS2 and dynamic erodibility Hydrological Processes 16(15), 30793089

[4] Riley, S. and F. Hancock. 1997. A rainfall simulator for hydrologic and erosion experiments on mines, with an example of its application at Ranger Uranium Mine, Northern Territory, Australia. AusIMM Proceedings, 1,3-8

[5] Riley, S., Mann, R., Hackney, P., Shrestha, S. 1999, Report on rainfall simulation trials Blue Mountains. Phase1. May-June 1999. UWS. Engineering Report CE14 24pp plus CDROM 